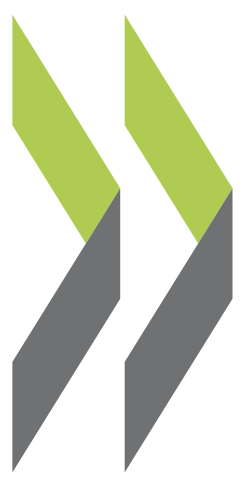

PEB Exchange, Programme on Educational Building 2001/05

The United Kingdom's Classrooms of the Future

\author{
Chris Bissell
}

https://dx.doi.org/10.1787/800301850353 


\section{THE \\ UNITED KINGDOM'S \\ CLASSROOMS OF THE FUTURE}

"It's lift off from mission control to boost science in the classroom as part of a GBP 10 million Classroom of the Future pilot scheme." This was reported in newspapers in the United Kingdom recently, but it does not give a full picture of what the project is all about.

Last year the UK Department for Education and Employment (DfEE) developed proposals for an initiative in school building design that became known as Classrooms of the Future. Its objective is to develop a number of pilot projects which explore different design options for the delivery of education in the 21 st century. The lessons learned from the projects will help shape guidance for the future design of schools.

The DfEE started by writing a discussion paper setting out the factors they expect to be the major drivers of change in school building design. These are:

- developments in education, such as the need to spread the expertise of the most able teachers more widely, or the impact of a longer learning period: day, week, term, year and life;

- the need to stimulate children to achieve more by, for example, designing educational environments that are themselves stimulating;

- changes in the organisation of the classroom environment to enable large groups (perhaps combining several classes) and small groups to be taught effectively in a space that also facilitates individual learning;

- developments in information and communications technology (ICT) which will affect the design of both learning and teaching spaces;

- the need for flexibility and adaptability, both to prevent premature obsolescence of design and to allow spaces to be personalised by teachers and learners;

- the impact of a major increase in the community use of school buildings;

- developments in building technology affecting both permanent and temporary accommodation;

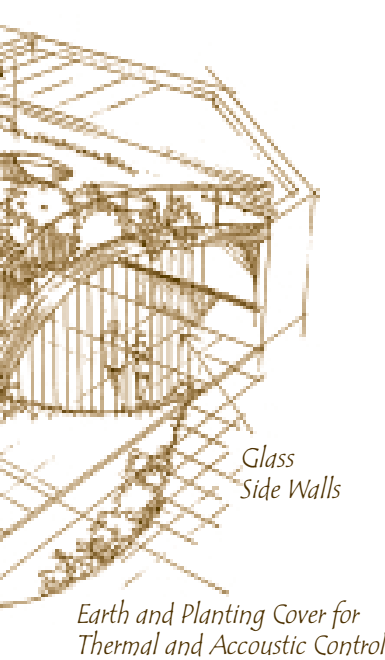

Proposal submitted by the

Hounslow Education Authority

- the increasing emphasis on sustainable construction for all development, requiring buildings to have a positive impact on the environment.

The paper was then sent to local education authorities (LEAs), with the invitation to submit proposals for carrying out pilot projects. The DfEE asked them to look at the ideas, outline how they might develop them and add ideas of their own. The Department stressed that the initiative was about testing innovative new building designs rather than just exploring developments in ICT. Also, because these are to be pilot projects, they needed to be capable of being replicated in other situations, even if in modified forms. However, there was also scope for exciting and one-off designs that might stimulate other developments in educational building design.

The DfEE warned LEAs that the budget was GBP 10 million and that this was expected to fund about 30 projects in perhaps 10 authorities. Despite the limited resources, great interest was shown. Out of the 150 LEAs in England, 91 submitted proposals and the estimated cost of these exceeded GBP 75 million.

Twelve proposals, covering 32 pilot projects, were shortlisted to participate in the initiative. Some of them are futuristic while others are much more down-to-earth, as can be seen from the details of some of the proposals:

1. Three projects will be developed in partnership with a science museum. The proposals combine innovative approaches to motivational learning with applications of new technologies, including renewable energy sources, and new uses of ICT. Included will be interactive learning experiences, using walls, ceilings and floors - but each project is different, being tailored to the age ranges for lower, middle and upper schools. 

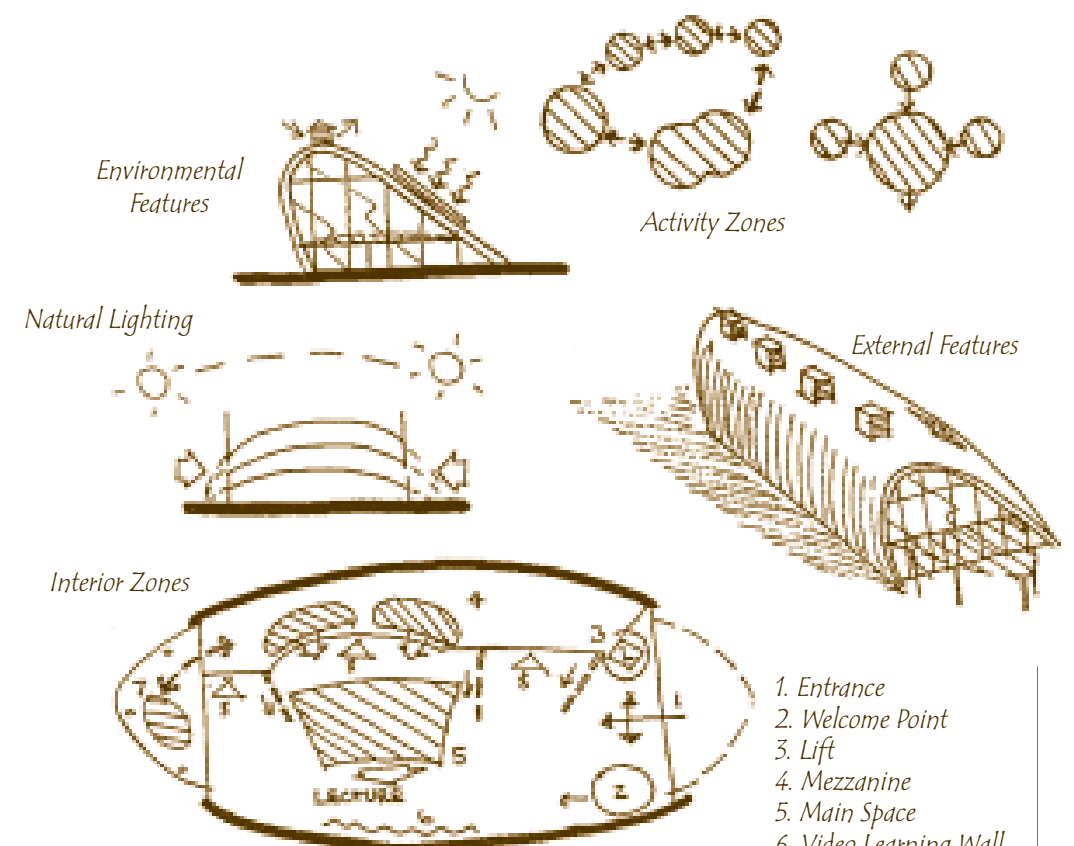

1. Entrance

2. Welcome Point

3. Lift

4. Mezzanine

5. Main Space

6. Video Learning Wall

7. Terrace

8. Storage/Utility conservation issues and an archaeological inheritance from the Stone Age to the Iron Age. The satellites will be constructed at two schools. There will be links to remote centres, from the Scottish Glens to the Galapagos Islands.

6. A prototype highly ICT resourced, demountable, "clip-on" classroom will be developed for use throughout Camden and with applications elsewhere. It will be designed to tackle the problems of adapting/extending urban schools, with limited site areas. The prototype will be designed to be clipped on to the exterior of a building or, in a simpler form, to be installed within a large internal space, such as a hall. Two projects will be constructed, each around $100 \mathrm{~m}^{2}$.
2. The construction of three projects, also for different age ranges, will draw on advanced thinking in architecture and design, combined with practical educational expertise and new technologies. The classrooms will challenge the traditional roles of teacher and learner, encourage creative thinking and provide a genuinely new experience for all those involved in the learning process. Partners include Future Systems, Cap Gemini, Ultralab and the University of the First Age. The projects are likely to be modular, high technology buildings.

3. Three pilot projects to be carried out will be capable of relocation, so that they can follow population growth. These learning centres, composed of three class equivalents, will provide secondary level education in more remote areas, where population levels do not warrant provision of a whole school. One of these could form the nucleus of a new school, if population grows, or be moved elsewhere if it falls. Partners include Cranfield University.

4. One project offers a space mission control centre, realtime night astronomy during daylight hours in the UK through remote control of satellites on the dark side of the planet and international links. Collaboration is taking place with the National Space and Science Centre in Leicester. Input is also promised from the Royal Navy.

5. One proposal includes projects on three sites, a hub and two satellites, with links to all secondary schools in the Southwest Grid for Learning. The hub will be located at a Site of Special Scientific Interest (SSSI), allowing the opportunity to explore seven distinct habitats,
7. Three pilot projects will explore and develop solutions to the challenge of providing and sustaining the educational needs of pupils attending small rural schools. High technology links will be developed between the primary schools and the high school to enable pupils to interact across distances and lessons to be taught to larger groups. The high school already has links with schools in France and Germany. The needs of rural communities will also be recognised in these projects. Innovative and sustainable design is promised.

8. Facilities will be created which allow learners to explore cyberspace, outer space and the physical space in and around their school. The project, based in a primary school, will hold up to 60 pupils at a time. It will be comprised of one large space, two to four smaller rooms and a floor-to-ceiling observatory in the centre of the structure. The focal point will be a high powered telescope and there will also be a link to the Faulkes Telescope Project in Hawaii.

The DfEE will publish a review of how these pilot projects work out and, in the meantime, will post developments on the Web at www.dfee.gov.uk/schbldgs

\author{
Article contributed by: \\ Chris Bissell \\ Architects and Building Branch \\ Department for Education and Employment \\ Caxton House \\ 6-12 Tothill Street, Westminster \\ London SW1H 9NF, United Kingdom \\ Fax: 442072736762 \\ E-mail: chris.bissell@dfee.gov.uk
}

